\title{
Therapeutic use of dendritic cells to promote the extranodal priming of anti-tumor immunity
}

\section{Lu Chen ${ }^{1}$, Kellsye L. Fabian ${ }^{1}$, Jennifer L. Taylor ${ }^{2}$ and Walter J. Storkus 1,2,3*}

1 Department of Immunology, University of Pittsburgh School of Medicine, Pittsburgh, PA, USA

2 Department of Dermatology, University of Pittsburgh School of Medicine, Pittsburgh, PA, USA

${ }^{3}$ University of Pittsburgh Cancer Institute, Pittsburgh, PA, USA

\section{Edited by:}

Lisa Helene Butterfield, University of Pittsburgh, USA

\section{Reviewed by:}

James Harold Finke, Cleveland Clinic, USA

James Joseph Mulé, Moffitt Cancer Center, USA

\section{*Correspondence}

Walter J. Storkus, Departments of Dermatology and Immunology,

University of Pittsburgh, W10041.2

BST, 200 Lothrop Street, Pittsburgh,

PA 15213, USA

e-mail: storkuswj@upmc.edu
Ectopic lymphoid tissue, also known as tertiary lymphoid organs (TLO) develop adaptively within sites of chronic tissue inflammation, thereby allowing the host to efficiently crossprime specific immune effector cells within sites of disease. Recent evidence suggests that the presence of TLO in the tumor microenvironment (TME) predicts better overall survival. We will discuss the relevance of extranodal T cell priming within the TME as a means to effectively promote anti-tumor immunity and the strategic use of dendritic cell (DC)-based therapies to reinforce this clinically preferred process in the cancer-bearing host.

\section{Keywords: dendritic cells, extranodal, cross-priming, therapy, cancer}

\section{INTRODUCTION}

In the classical model of peripheral $\mathrm{T}$ cell activation, tissueresident dendritic cells (DCs) capture antigens (such as foreign pathogens, tumor cell debris, etc.) in an inflammatory microenvironment, leading to the migration of antigen-laden CCR7 ${ }^{+}$ DC to regional draining lymph nodes [LN; aka secondary lymphoid organs (SLO)], where activation of cognate T cells occurs (1-3). After appropriate proliferative expansion and maturation, $\mathrm{T}$ effector cells may then enter the blood circulation and be recruited into tissue sites where they are competent to recognize and react against relevant antigen-presenting cells, such as virally infected host cells or tumor cells (4). Recent evidence obtained in a range of translational and clinical models suggests, however, that this classical/conventional paradigm may be operationally overly simplistic, and that extranodal (cross)priming of antigen-specific $\mathrm{T}$ cells can occur in peripheral tissues, often times in conditionally established tertiary lymphoid organs (TLO) (5-9).

\section{SLO/TLO DEVELOPMENT: NATURAL AND INDUCED}

The developmental formation of SLO is believed to require the interaction of so-called lymphoid tissue inducer cells (LTi) bearing a $\mathrm{CD} 3{ }^{-} \mathrm{CD} 4^{+} \mathrm{CD} 45^{+} \mathrm{IL}-7 \mathrm{R}^{+} \mathrm{c}-\mathrm{Kit}^{+}$phenotype that produce lymphotoxin $\alpha / \beta[\mathrm{LT} \alpha / \beta$; Ref. $(10,11)]$ with $\mathrm{LT} \beta \mathrm{R}^{+}$stromal "organizer" cell populations that may derive from adipocyte precursors (12), leading to corollary stromal cell elaboration of the SLO homeostatic chemokines CCL19, CCL21, and CXCL13 (8, 9, 13-15). These chemokines sustain recruitment of LTi and other lymphocytes into SLO, resulting in the development of a mature lymphoid organ architecture [i.e., based on the formation of follicular structures containing B cells and surrounding "cortical" zones that are diffusely populated by $\mathrm{CD} 4^{+}$and $\mathrm{CD} 8^{+} \mathrm{T}$ cells, antigen-presenting cells (including CD11 ${ }^{+}$DC), and $\mathrm{PNAd}^{+}$ high-endothelial venules (HEV; $(8,15-19))$ ].

Naive $\left(\mathrm{CD}_{2} \mathrm{~L}^{+} \mathrm{CCR}^{+}\right) \mathrm{T}$ cells enter SLO via interaction with PNAd ${ }^{+}$HEV which are "decorated" with the CCR7 ligand chemokines CCL19 and CCL21 on their luminal surface, thereby facilitating lymphocyte extravasation/directed motility from the blood into the lymph node (20). Of these two chemokines, CCL21 may play the more dominant role in recruiting naïve lymphocytes into SLO, while CCL19 may be differentially cytoprotective in sustaining nodal populations of lymphocytes (20-22). Prolonged CCR7-mediated signaling into recruited $\mathrm{T}$ cells, leads to intrinsic upregulation of the sphingosine- 1 phosphate receptor 1, EDG1 (23), which is involved in the ultimate departure of primed $\mathrm{T}$ cell populations from SLO into the peripheral blood circulation $(24,25)$.

While classical SLO are encapsulated structures that develop in predictable locations as a consequence of normal immune system development, under pathologic conditions, ectopic lymphoid tissues (aka TLO) may develop in peripheral tissue sites of chronic inflammation $(13,26)$. TLO formation has been reported within inflamed organs of patients with rheumatoid arthritis (27-29), psoriatic arthritis (30), diabetes mellitus (31-33), autoimmune gastritis [AIG; Ref. (32)], juvenile dermatomyositis (34), and Sjögren's syndrome (35), among others. TLO formation has also been identified in the lungs of influenza virus-infected mice (36), the livers of hepatitis C virus (HCV)-infected patients (37) and in the stomachs of patients infected with Helicobacter pylori (38). "Dysfunctional" human lung allografts exhibiting chronic inflammatory responses have also been found to commonly contain TLO (17).

Furthermore, a burgeoning literature supports tumorassociated TLO as important sites of extranodal T cell priming 
and epitope spreading in the responder $\mathrm{T}$ cell repertoire $(13,39)$. TLO have been identified in a subset of human melanoma lesions, in which mature DC were found to maintain intimate contact with recruited $\mathrm{T}$ cell populations, consistent with the notion of operational extranodal (cross)priming within the tumor microenvironment (TME) $(40,41)$. Similar results have been reported for murine melanoma models $(7,8)$. In line with this model, naïve lymphocytes have been identified in TLO within pulmonary lesions of patients with lung cancer, making it likely that these immune cells encounter their cognate antigen for the first time and develop into antigen-specific T effector cells within the TME in vivo $(16,42)$. TLO featuring DC/Type-1 T cell clusters proximal to B cell "nests" have also been identified in human non-smallcell lung cancer specimens (43). In such instances, the density of mature DC found in TLO appeared to be associated with improved long term survival $(6,43)$. In a subset of patients with breast cancer, HEV have been found in close proximity to $\mathrm{LT}^{+}{ }^{+} \mathrm{LAMP}^{+}$ DC in association with profound B/T cell infiltrates in the TME and a more favorable clinical outcome (44). Furthermore, Mulé and colleagues have recently performed a metagene analysis on human (Stage IV, non-locoregional) melanoma metastases and identified a 12-chemokine gene signature (i.e., CCL2, CCL3, CCL4, CCL5, CCL8, CCL18, CCL19, CCL21, CXCL9, CXCL10, CXCL11, CXCL13) correlating with the presence of TLO (containing $\mathrm{CD} 20^{+} \mathrm{B}$ cell follicles with prominent areas of $\mathrm{CD} 4^{+}$and $\mathrm{CD}^{+}{ }^{+}$cells, but not FoxP3 ${ }^{+} \mathrm{T}_{\text {reg }}$ cells), with better overall survival noted in the $\mathrm{TLO}^{+}$subset of patients (41). In a similar vein, Gu-Trantien et al. (45) have also recently observed that the presence of breast cancer infiltrating follicular $\mathrm{CD} 4^{+} \mathrm{T}$ helper cells (Tfh; expressing CD200, FBLN7, ICOS, SGPP2, SH2D1A, TIGIT, and PDCD1/PD-1, and producing the CXCL13 chemokine) may be directly correlated with; (i) the degree of tumor-infiltrating lymphocytes (TIL), (ii) the formation of TLO-like structures in cancer tissue, and (iii) improved patient clinical response to pre-operative chemotherapy and/or post-surgical disease-free survival.

The conditional formation of TLO in peripheral tissues appears to require the coordinate participation of a similar cast of cellular participants, soluble mediators, and signaling pathways associated with the orchestration of SLO development $(14,15)$. Ectopic delivery of LT $\alpha / \beta$ or LIGHT (aka TNFSF-14 or CD258) promotes PNAd $^{+}$HEV, CCL19/CCL21 production, massive naïve T cell infiltration, and (tumor-specific) cross-priming in the context of TLO structures $(9,18,36,46-49)$. For example, targeted therapeutic delivery of LT $\alpha$ into the TME via the administration of a fusion protein encompassing the LT $\alpha$ molecule linked to an antibody recognizing a tumor plasma membrane-associated disialoganglioside GD2 (i.e., ch14.18-LT $\alpha$ ) resulted in slowed tumor progression and the establishment of mature TLO structures within 9 days of treatment initiation (8). The LT $\beta$ R ligands LT $\alpha / \beta$ and LIGHT appear to act directly on endothelial cells and DC in activating $\mathrm{NF} K \mathrm{~B}$ and promoting the expression of adhesion molecules, such as PNAd, VCAM-1, E-selectin, and ICAM-1 by HEV and IL-12p70 production from DC (50-52). In particular, LIGHT is essential for DC-mediated cross-priming of antigen-specific Type-1 T cells (53). Indeed, ectopic expression of LIGHT in the TME elicits profound infiltration and cross-priming of naïve anti-tumor $\mathrm{T}$ cells in concert with upregulated stromal cell production of TLOassociated chemokines (CCL21, CXCL9, CXCL10, and CXCL13), increased expression of vascular adhesion molecules (MAdCAM1, VCAM-1, PNAd), and the presence of mature DC within the TME (9). Interestingly, DC, natural killer (NK) cells, and even $B$ cells can serve as LT $\alpha / \beta$ producers in pro-inflammatory environments, allowing for the establishment of an autocrine feedforward loop promoting TLO development in peripheral tissues $(36,54-59)$. Consistent with these findings noted for pro-TLO immunobiology of LT $\beta R$ ligands, blockade of the LT $\beta R$ precludes formation of TLO in vivo (60).

In a similar manner, induced expression or ectopic delivery of LT $\beta$ R downstream mediators, CCL19 or CCL21, in the TME results in inhibition of tumor growth or complete rejection of established tumors associated with increased infiltration by $\mathrm{CD}^{+}{ }^{+} \mathrm{CCR} 7^{+}$ $\mathrm{T}$ cells and/or DCs in a range of cancer models (32, 61-70). Interestingly, these interventional maneuvers may also reduce frequencies of tumor-associated immunosuppressive $\mathrm{T}_{\text {reg }}$ cells and MDSC (61).

During the ontogeny of TLO in peripheral tissues, lymphatic vessels (i.e., PNAd ${ }^{+}$, MAdCAM- $1^{+}, \mathrm{LYVE}^{+} 1^{+}$, and/or Prox- $1^{+}$ HEV) and disorganized clusters of APC and infiltrating lymphocytes appear in advance of canonical mature lymphoid organ architecture characterized by B cell follicular regions $(19,71)$. Signals that instigate the diffuse-to-organized structural transition of TLO may be provided by cognate $\mathrm{T}$ cell recognition of relevant target cell populations within nascent TLO $(15,72)$. It is important to note, however, that immature TLO have been oft-associated with locoregional immune sequelae including manifestations of autoimmunity and anti-tumor efficacy $(5,32,71)$. Hence, while mature TLO may ultimately develop in the chronic disease setting, clinical meaningful immunobiology occurs in advance of such structural developments.

\section{THERAPEUTIC PROMOTION OF TLO}

If the formation of TLO allows for extranodal (cross)priming of antigen-specific $\mathrm{T}$ cells that are linked to disease pathogenesis (i.e., autoimmunity) or resolution (i.e., infectious disease, cancer), then means by which to prevent or enhance TLO development, respectively, in affected tissues would be anticipated to impact clinical outcome. Perhaps the most strategically simple means by which to apply this paradigm in the cancer setting reflects the implantation of SLO/TLO directly into the TME. Recently, scaffold-based lymphoid tissue engineering has been developed as a means to transplant "intact" TLO directly into tumors in order to affect clinical benefit (73). A previously mentioned alternative to this strategy is clearly the delivery of the LT $\beta$ R ligands LT $\alpha, \mathrm{LT} \beta$, or LIGHT, agonist anti-LT $\beta \mathrm{R}$ antibodies or downstream TLO-associated chemokines (CCL19, CCL21, CXCL13) via protein-based or genetic therapy in order to instigate the locoregional development of TLO in the TME leading to inhibition of tumor growth in vivo and extended overall survival $(8,9,48,74,75)$.

\section{USE OF DC-BASED THERAPY TO PROMOTE EXTRANODAL PRIMING OF ANTI-TUMOR T CELLS}

It also appears that the administration of appropriately activated/engineered DC is sufficient to nucleate and/or maintain the 
development of TLO in vivo $(36,72)$. For instance, mice vaccinated sub-cutaneously with syngenic DC loaded with apoptotic/necrotic B16 melanoma cell debris develop operational TLO [pseudocapsule; $\mathrm{PNAd}^{+}$vascular endothelial cells (VEC), T cell/DC infiltrates] at sites of injection, leading to the activation of protective anti-tumor immunity (72). DC genetically engineered to secrete high-levels of CCL21 (DC.CCL21) and injected directly into B16 murine melanomas promote strong extranodal $\mathrm{T}$ cell crosspriming/recruitment into the TME, even in LT $\alpha-/-$ mice that lack SLO $(8,68)$. The superiority of DC.CCL2 1 in enhancing the cross-priming of protective Type- 1 anti-tumor $\mathrm{T}$ cell responses has also been confirmed in alternate murine models $(76,77)$.

In our recent paper (5), we noted that DC engineered to express the Type-1 transactivator protein T-bet (DC.Tbet) and injected directly into sarcomas growing progressively in C57BL/6 mice, led to the cross-priming of protective immunity that was independent of host $\mathrm{CD} 11 \mathrm{c}^{+}$or $\mathrm{BATF}^{+} \mathrm{DC}$ or the ability of the injected DC.Tbet to migrate to SLO. Instead, we detected the rapid recruitment of $\mathrm{NK}$ cells and naïve $\mathrm{T}$ cells into the TME within $48 \mathrm{~h}$ of DC.Tbet administration, and the differentiation of these TIL into Type-1 effector cells in situ within the TME. As shown in Figure 1, we observed a diffuse but interactive collection of CD11c ${ }^{+}$DC and Tbet ${ }^{+}$cells [including both T cells (5) and $\mathrm{B} 220^{+} \mathrm{B}$ cells] within the TME of MCA205 sarcomas by $48 \mathrm{~h}$ post-treatment with DC.Tbet, but not control DC. PNAd ${ }^{+} \mathrm{HEV}$ were not evident at this early time point, but were readily imaged in proximity to large DC-Tbet ${ }^{+}$lymphocyte clusters by 5 days posttreatment with DC.Tbet (but not control DC). These data suggest that extranodal priming of protective immunity using therapeutic DC delivery occurs in advance of the formal adoption of classical TLO anatomic structures within the TME (Figure 2), and that indeed, the development of such Type-1 cognate immunity (and its pro-inflammatory signals) in the TME may be required for subsequent evolution of mature TLO formatting, as described by Schrama et al. (8). Interestingly, a gene array analysis of DC.Tbet versus control DC did not reveal any striking differences in expression of LTA, LTB, LIGHT, CCL19, CCL21, or CXCL13 mRNA transcripts, suggesting a potentially novel mechanism associated with early TLO development triggered by this DC-based therapy [(5) and Chen, unpublished data]. In this regard, we noted a striking enhancement in DC.Tbet production of IL-36 $\gamma / \mathrm{IL}-1 \mathrm{~F} 9$ (>34-fold; Chen, unpublished data). IL-36 $\gamma$ is a novel IL-1 family member cytokine that has been previously reported to be a potent recruiter and activator of naïve T cells that develop strong Type-1 functional polarity $(78,79)$. As in the case of LT $\beta R$ ligands, IL36 also triggers NFKB activation in IL-36R ${ }^{+}$DC (79-82), which may prove pivotal for autocrine potentiation of Type-1 DC function and a pro-TLO TME. Whether tumor-associated VEC express IL-36R and activated NFkb in response to IL-36 remains an unanswered question. We are currently evaluating the impact of IL-36 $\gamma$ knock-down in DC.Tbet in order to determine the direct relevance of IL-36 $\gamma$ in the development of TLO and protective immunity in the TME of mice treated with intratumoral administration of DC.Tbet.

\section{SUMMARY AND FUTURE PERSPECTIVES}

In the cancer setting, the ability of the host to develop ectopic lymphoid organs (TLO) within or proximal to sites of active disease appears to represent a positive prognostic factor for overall patient survival. TLO represent a regional "factory" in which naïve T cells (and B cells) may be cross-primed by tumor-resident antigen-presenting cells, such as DC, leading to poly-specific adaptive immunity that may limit disease progression and conceivably metastatic spread. By limiting the need for antigen-loaded DC to

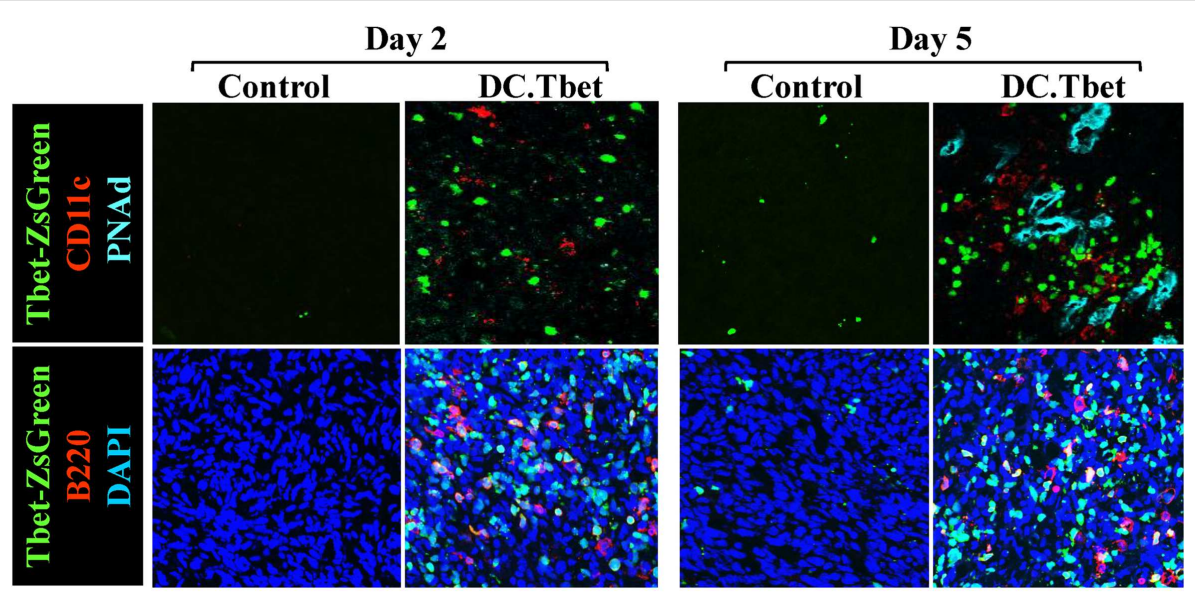

FIGURE 1 | Intratumoral administration of dendritic cells engineered to express T-bet/TBX21 (DC.Tbet) promote the rapid infiltration of Type-1-polarized lymphocytes and dendritic cells and the development of PNAd ${ }^{+}$endothelial cells (i.e., HEV). Tbet-ZsGreen Tg mice were injected sub-cutaneously with syngenic MCA205 sarcoma cells and tumors allowed to progressively grow for 7 days, at which time control DC (Control) or DC engineered with recombinant adenovirus to express murine T-bet cDNA were inoculated directly into tumors, as previously described (5). Two or 5 days after DC injection, the mice were euthanized and tumor sections evaluated by fluorescence microscopy for expression of Tbet-ZsGreen protein, CD11c la marker of DC), B220 (a B cell marker), and PNAd (i.e., Peripheral lymph Node Addressin; a high endothelial venule (HEV) cell marker). PNAd ${ }^{+} \mathrm{HEV}$ were not observed by 2 days post-treatment, but became prevalent by 5 days post-injection of DC.Tbet cells. B, T, and NK cell infiltrates into DC.Tbet [Figure 1 and (5)] exhibited a diffuse distribution pattern in day 2 and day 5 DC. Tbet-treated tumors. Type-1 polarity in infiltrating cells is denoted by nuclear expression of Tbet-ZsGreen. Data are representative of images obtained in three independent experiments performed. 


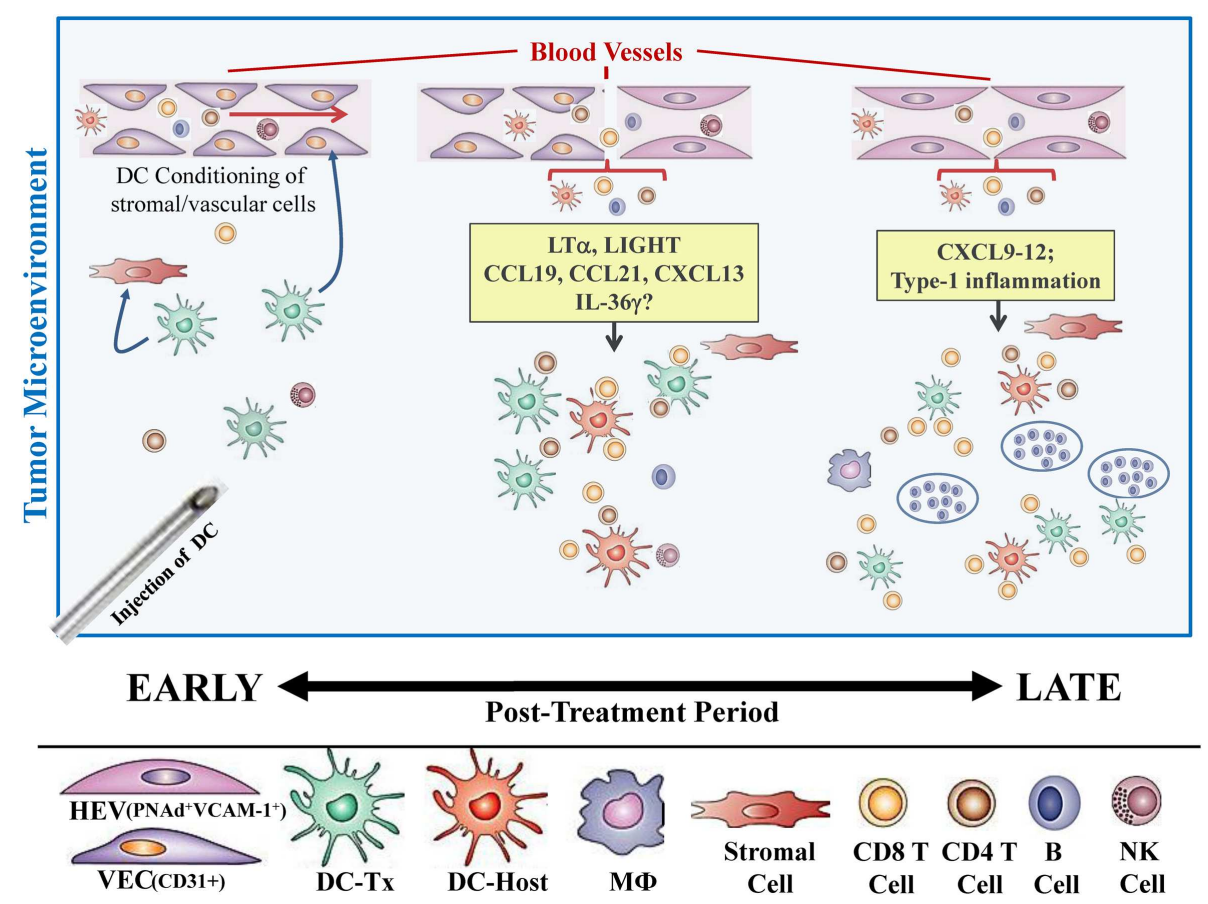

FIGURE 2 | Hypothetical paradigm for extranodal priming of T cells after intratumoral administration of DC.Tbet cells. Injection of DC.Tbet (but not control DC) into the TME leads to the conditioning of tumor-associated stromal cells and vascular endothelial cells (VEC), resulting in stromal cell production of chemokines recruiting naïve leukocytes ( $B, T, N K$ cells) and VEC expression of adhesion molecules, such as VCAM-1, as early as day 2 post-treatment [Figure 1 and (5)]. Recruited lymphocytes are assembled in diffuse patterns around CD $11 \mathrm{c}^{+}$(both injected and host) DC and have already acquired Type-1 functional polarization, based on expression of the Tbet reporter protein (Tbet-ZsGreen) in vivo. PNAd + HEV are not formally required for early recruitment of naïve $T$ cells into the TME since these structures do not become discernible until later time points [i.e., day 5; Figure 1 and (5)]. $\mathrm{B} 22 \mathrm{O}^{+} \mathrm{B}$ cells recruited into the TME as a consequence of treatment with DC.Tbet cells are not organized into follicle-like structures during the day 2-5 time period, but may become organized in this manner at even later time points (i.e., $\geq$ day 9 post-therapy), based on previous reports employing alternate immunotherapeutic interventions, such as ch14.18-LT $\alpha$ (8). While therapeutic benefits in our model were largely $T$ cell-dependent and detectable prior to the establishment of formal TLO structures (based on the development of B cell follicles), the presence of "mature" TLO in human tumors has been associated with better clinical prognosis. migrate to tumor-draining SLO, and the corollary requirement of SLO-primed $\mathrm{T}$ cells to be recruited back into tumor sites, TLO may operationally increase the efficiency of anti-tumor T cell cross-priming and the therapeutic action of such $\mathrm{T}$ effector cells in the TME. Translational studies clearly suggest that TLO formation in the TME may be therapeutically fostered by the directed delivery of LT $\beta$ R ligands in both protein- and genebased formats. At present, LT $\beta$ R agonist-based therapies are in their infancy with only rhLT $\alpha$ thus far evaluated in phase I clinical trials, where minimal anti-tumor efficacy was observed in patients with melanoma or renal cell carcinoma (83). The inability to focus this potent TLO induction agent in appropriate sites of disease in order to most effectively recruit and activate protective immunity in treated patients must be considered a possible limitation to the current treatment strategy. The ligation of rhLT $\alpha$ to a cancerspecific antibody or the intratumoral administration of this agent could improve anti-tumor efficacy and coordinately reduce current off-target toxicities [i.e., grade III chill, grade III fever, and grade III dyspnea; Ref. (83)].

Improved targeted delivery of LT $\beta R$ ligand or downstream chemokine gene therapies is conceptually attractive given pre-clinical results in murine tumor models. To date, however, only a recombinant adenovirus encoding hCCL21 has been developed for phase I clinical application, with the intent to deliver rAd.CCL21-infected patient DC directly into tumors in patients with late stage human lung cancer (84) or in vaccine formulations applied to patients with melanoma (85). Although this approach requires further optimization of the clinical vector based on low levels of CCL21 produced by engineered DC, melanoma patients treated at the lowest dose tier of DC.CCL21 did develop lymph node-like structures based on immunohistochemical analysis of vaccination site biopsies (James Mulé, personal communication). Our own pre-clinical data would support the clinical application of DC.Tbet directly into accessible tumor lesions as a means to drive TLO development and protective immunity in the TME. Motivation for the development of prospective phase I trials using DC.Tbet cells will be intensified when the underlying mechanism of action for this treatment modality has been defined.

Finally, in a related note, antagonists of LT $\beta$ R ligands (such as BTLA and CD160) have been shown to be immunosuppressive molecules in inhibiting DC homeostasis as well as the protective effector functions mediated by T cells and NK cells $(74,86-90)$. 
It is therefore conceivable that endogenous levels of TLO development and corollary anti-tumor immunity may be bolstered therapeutically as a consequence of administering agents (i.e., antagonist antibodies or DC genetically engineered to produce specific inhibitors locoregionally in the TME) that are capable of blocking the action of BTLA or CD160 in vivo.

\section{ACKNOWLEDGMENTS}

This work was supported by NIH R01 grant CA169118 (Walter J. Storkus). This project used the University of Pittburgh Cancer Institute's Vector Core Facility supported by the NIH CCSG award P30 CA047904.

\section{REFERENCES}

1. Nierkens S, Tel J, Janssen E, Adema GJ. Antigen cross-presentation by dendritic cell subsets: one general or all sergeants? Trends Immunol (2013) 34:361-70. doi:10.1016/j.it.2013.02.007

2. Apetoh L, Locher C, Ghiringhelli F, Kroemer G, Zitvogel L. Harnessing dendritic cells in cancer. Semin Immunol (2011) 23:42-9. doi:10.1016/j.smim.2011.01.003

3. Melief CJ. Cancer immunotherapy by dendritic cells. Immunity (2008) 29:372-83. doi:10.1016/j.immuni.2008.08.004

4. Mueller SN, Gebhardt T, Carbone FR, Heath WR. Memory T cell subsets, migration patterns, and tissue residence. Annu Rev Immunol (2013) 31:137-61. doi:10.1146/annurev-immunol-032712-095954

5. Chen L, Taylor JL, Sabins NC, Lowe DB, Qu Y, You Z, et al. Extranodal induction of therapeutic immunity in the tumor microenvironment after intratumoral delivery of Tbet gene-modified dendritic cells. Cancer Gene Ther (2013) 20:469-77. doi:10.1038/cgt.2013.42

6. Fridman WH, Dieu-Nosjean MC, Pagès F, Cremer I, Damotte D, SautèsFridman C, et al. The immune microenvironment of human tumors: general significance and clinical impact. Cancer Microenviron (2013) 6:117-22. doi:10.1007/s12307-012-0124-9

7. Thompson ED, Enriquez HL, Fu YX, Engelhard VH. Tumor masses support naive $\mathrm{T}$ cell infiltration, activation, and differentiation into effectors. J Exp Med (2010) 207:1791-804. doi:10.1084/jem.20092454

8. Schrama D, Voigt H, Eggert AO, Xiang R, Zhou H, Schumacher TN, et al. Immunological tumor destruction in a murine melanoma model by targeted LT $\alpha$ independent of secondary lymphoid tissue. Cancer Immunol Immunother (2008) 57:85-95. doi:10.1007/s00262-007-0352-x

9. Yu P, Lee Y, Liu W, Chin RK, Wang J, Wang Y, et al. Priming of naive T cells inside tumors leads to eradication of established tumors. Nat Immunol (2004) 5:141-9. doi:10.1038/ni1029

10. Carragher DM, Rangel-Moreno J, Randall TD. Ectopic lymphoid tissues and local immunity. Semin Immunol (2008) 20:26-42. doi:10.1016/j.smim.2007.12. 004

11. Mebius RE, Rennert P, Weissman IL. Developing lymph nodes collect $\mathrm{CD} 4^{+} \mathrm{CD} 3^{-} \mathrm{LT}^{+}{ }^{+}$cells that can differentiate to APC, NK cells, and follicular cells but not T or B cells. Immunity (1997) 7:493-504. doi:10.1016/S1074-7613(00) 80371-4

12. Bénézech C, Mader E, Desanti G, Khan M, Nakamura K, White A, et al. Lymphotoxin- $\beta$ receptor signaling through NF-кB2-RelB pathway reprograms adipocyte precursors as lymph node stromal cells. Immunity (2012) 37:721-34. doi:10.1016/j.immuni.2012.06.010

13. Stranford S, Ruddle NH. Follicular dendritic cells, conduits, lymphatic vessels, and high endothelial venules in tertiary lymphoid organs: parallels with lymph node stroma. Front Immunol (2012) 3:350. doi:10.3389/fimmu.2012.00350

14. Randall TD, Carragher DM, Rangel-Moreno J. Development of secondary lymphoid organs. Annu Rev Immunol (2008) 26:627-50. doi:10.1146/annurev. immunol.26.021607.090257

15. Cupedo T, Jansen W, Kraal G, Mebius RE. Induction of secondary and tertiary lymphoid structures in the skin. Immunity (2004) 21:655-67. doi:10.1016/j. immuni.2004.09.006

16. de Chaisemartin L, Goc J, Damotte D, Validire P, Magdeleinat P, Alifano M, et al. Characterization of chemokines and adhesion molecules associated with $\mathrm{T}$ cell presence in tertiary lymphoid structures in human lung cancer. Cancer Res (2011) 71:6391-9. doi:10.1158/0008-5472.CAN-11-0952
17. Sato M, Hirayama S, Matsuda Y, Wagnetz D, Hwang DM, Guan Z, et al. Stromal activation and formation of lymphoid-like stroma in chronic lung allograft dysfunction. Transplantation (2011) 91:1398-405. doi:10.1097/TP. 0b013e31821b2f7a

18. Drayton DL, Ying X, Lee J, Lesslauer W, Ruddle NH. Ectopic LT $\alpha / \beta$ directs lymphoid organ neogenesis with concomitant expression of peripheral node addressin and a HEV-restricted sulfotransferase. J Exp Med (2003) 197:1153-63. doi:10.1084/jem.20021761

19. Ruddle NH. Lymphoid neo-organogenesis: lymphotoxin's role in inflammation and development. Immunol Res (1999) 19:119-25. doi:10.1007/BF02786481

20. Comerford I, Harata-Lee Y, Bunting MD, Gregor C, Kara EE, McColl SR. A myriad of functions and complex regulation of the CCR7/CCL19/CCL21 chemokine axis in the adaptive immune system. Cytokine Growth Factor Rev (2013) 24:269-83. doi:10.1016/j.cytogfr.2013.03.001

21. Link A, Vogt TK, Favre S, Britschgi MR, Acha-Orbea H, Hinz B. Fibroblastic reticular cells in lymph nodes regulate the homeostasis of naive T cells. Nat Immunol (2007) 8:1255-65. doi:10.1038/ni1513

22. Luther SA, Tang HL, Hyman PL, Farr AG, Cyster JG. Coexpression of the chemokines ELC and SLC by T zone stromal cells and deletion of the ELC gene in the plt/plt mouse. Proc Natl Acad Sci U S A (2000) 97:12694-9. doi:10.1073/pnas.97.23.12694

23. Shannon LA, McBurney TM, Wells MA, Roth ME, Calloway PA, Bill CA, et al CCR7/CCL19 controls expression of EDG-1 in T cells. J Biol Chem (2012) 287:11656-64. doi:10.1074/jbc.M111.310045

24. Britschgi MR, Link A, Lissandrin TK, Luther SA. Dynamic modulation of CCR7 expression and function on naive $\mathrm{T}$ lymphocytes in vivo. J Immunol (2008) 181:7681-8.

25. Pham TH, Okada T, Matloubian M, Lo CG, Cyster JG. S1P1 receptor signaling overrides retention mediated by $\mathrm{G}$ alpha I-coupled receptors to promote T cell egress. Immunity (2007) 28:122-33. doi:10.1016/j.immuni.2007.11. 017

26. Pabst O, Herbrand H, Bernhardt G, Förster R. Elucidating the functional anatomy of secondary lymphoid organs. Curr Opin Immunol (2004) 16:394-9. doi:10.1016/j.coi.2004.05.014

27. Weyand CM, Goronzy JJ. Ectopic germinal center formation in rheumatoid synovitis. Ann N Y Acad Sci (2003) 987:140-9. doi:10.1111/j.1749-6632.2003. tb06042.x

28. Kim EA, Lee KS, Johkoh T, Kim TS, Suh GY, Kwon OJ, et al. Interstitial lung diseases associated with collagen vascular diseases: radiologic and histopathologic findings. Radiographics (2002) 22:S151-65. doi:10.1148/radiographics.22. suppl_1.g02oc04s151

29. Rangel-Moreno J, Hartson L, Navarro C, Gaxiola M, Selman M, Randall TD. Inducible bronchus-associated lymphoid tissue (iBALT) in patients with pulmonary complications of rheumatoid arthritis. J Clin Invest (2006) 116:3183-94. doi:10.1172/JCI28756

30. Cañete JD, Santiago B, Cantaert T, Sanmartí R, Palacin A, Celis R, et al. Ectopic lymphoid neogenesis in psoriatic arthritis. Ann Rheum Dis (2007) 66:720-6. doi:10.1136/ard.2006.062042

31. Dresch C, Leverrier Y, Marvel J, Shortman K. Development of antigen crosspresentation capacity in dendritic cells. Trends Immunol (2012) 33:381-8. doi:10.1016/j.it.2012.04.009

32. Winter S, Rehm A, Wichner K, Scheel T, Batra A, Siegmund B, et al. Manifestation of spontaneous and early autoimmune gastritis in CCR7-deficient mice. Am J Pathol (2011) 179:754-65. doi:10.1016/j.ajpath.2011.04.012

33. Heath WR, Belz GT, Behrens GM, Smith CM, Forehan SP, Parish IA, et al. Cross-presentation, dendritic cell subsets, and the generation of immunity to cellular antigens. Immunol Rev (2004) 199:9-26. doi:10.1111/j.0105-2896.2004. 00142.x

34. López De Padilla CM, Vallejo AN, Lacomis D, McNallan K, Reed AM. Extranodal lymphoid microstructures in inflamed muscle and disease severity of new-onset juvenile dermatomyositis. Arthritis Rheum (2009) 60:1160-72. doi:10.1002/art.24411

35. Bombardieri M, Pitzalis C. Ectopic lymphoid neogenesis and lymphoid chemokines in Sjogren's syndrome: at the interplay between chronic inflammation, autoimmunity and lymphomagenesis. Curr Pharm Biotechnol (2012) 13:1989-96. doi:10.2174/138920112802273209

36. GeurtsvanKessel CH, Willart MA, Bergen IM, van Rijt LS, Muskens F, Elewaut D, et al. Dendritic cells are crucial for maintenance of tertiary lymphoid structures 
in the lung of influenza virus-infected mice. J Exp Med (2009) 206:2339-49. doi:10.1084/jem.20090410

37. Mosnier JF, Degott C, Marcellin P, Hénin D, Erlinger S, Benhamou JP. The intraportal lymphoid nodule and its environment in chronic active hepatitis $\mathrm{C}$ : an immunohistochemical study. Hepatology (1993) 17:366-71. doi:10.1002/hep. 1840170304

38. Mazzucchelli L, Blaser A, Kappeler A, Schärli P, Laissue JA, Baggiolini M, et al. BCA-1 is highly expressed in Helicobacter pylori-induced mucosa-associated lymphoid tissue and gastric lymphoma. J Clin Invest (1999) 104:R49-54. doi:10.1172/JCI7830

39. McMahon EJ, Bailey SL, Castenada CV, Waldner H, Miller SD. Epitope spreading initiates in the CNS in two mouse models of multiple sclerosis. Nat Med (2005) 11:335-9. doi:10.1038/nm1202

40. van Baren N, Coulie PG. Ongoing adaptive immune responses in the microenvironment of melanoma metastases. Ann N Y Acad Sci (2013) 1284:62-5. doi: $10.1111 /$ nyas. 12093

41. Messina JL, Fenstermacher DA, Eschrich S, Qu X, Berglund AE, Lloyd MC, et al. 12-Chemokine gene signature identifies lymph node-like structures in melanoma: potential for patient selection for immunotherapy? Sci Rep (2012) 2:765. doi:10.1038/srep00765

42. Pagès F, Galon J, Dieu-Nosjean MC, Tartour E, Sautès-Fridman C, Fridman WH. Immune infiltration in human tumors: a prognostic factor that should not be ignored. Oncogene (2010) 29:1093-102. doi:10.1038/onc.2009.416

43. Dieu-Nosjean MC, Antoine M, Danel C, Heudes D, Wislez M, Poulot V, et al. Long-term survival for patients with non-small-cell lung cancer with intratumoral lymphoid structures. J Clin Oncol (2008) 26:4410-7. doi:10.1200/JCO. 2007.15.0284

44. Martinet L, Filleron T, Le Guellec S, Rochaix P, Garrido I, Girard JP. High endothelial venule blood vessels for tumor-infiltrating lymphocytes are associated with lymphotoxin $\beta$-producing dendritic cells in human breast cancer. J Immunol (2013) 19:2001-8. doi:10.4049/jimmunol.1300872

45. Gu-Trantien C, Loi S, Garaud S, Equeter C, Libin M, de Wind A, et al. CD4 ${ }^{+}$ follicular helper $\mathrm{T}$ cell infiltration predicts breast cancer survival. J Clin Invest (2013) 123:2873-92. doi:10.1172/JCI67428

46. Onder L, Danuser R, Scandella E, Firner S, Chai Q, Hehlgans T, et al. Endothelial cell-specific lymphotoxin- $\beta$ receptor signaling is critical for lymph node and high endothelial venule formation. J Exp Med (2013) 210:465-73. doi:10.1084/ jem.20121462

47. Kanodia S, Da Silva DM, Karamanukyan T, Bogaert L, Fu YX, Kast WM. Expression of LIGHT/TNFSF14 combined with vaccination against human papillomavirus Type 16 E7 induces significant tumor regression. Cancer Res (2010) 70:3955-64. doi:10.1158/0008-5472.CAN-09-3773

48. Loeffler M, Le'Negrate G, Krajewska M, Reed JC. Attenuated Salmonella engineered to produce human cytokine LIGHT inhibit tumor growth. Proc Natl Acad Sci U S A (2007) 104:12879-83. doi:10.1073/pnas.0701959104

49. Lee Y, Chin RK, Christiansen P, Sun Y, Tumanov AV, Wang J, et al. Recruitment and activation of naive $\mathrm{T}$ cells in the islets by lymphotoxin beta receptor-dependent tertiary lymphoid structure. Immunity (2006) 25:499-509. doi:10.1016/j.immuni.2006.06.016

50. Suna S, Sakata Y, Sato H, Mizuno H, Nakatani D, Shimizu M, et al. Upregulation of cell adhesion molecule genes in human endothelial cells stimulated by lymphotoxin- $\alpha$ : DNA microarray analysis. J Atheroscler Thromb (2008) 15:160-5. doi:10.5551/jat.E553

51. Madge LA, Kluger MS, Orange JS, May MJ. Lymphotoxin- $\alpha 1 / \beta 2$ and LIGHT induce classical and noncanonical NF- $\mathrm{KB}$-dependent pro-inflammatory gene expression in vascular endothelial cells. J Immunol (2008) 180:3467-77.

52. Morel Y, Truneh A, Costello RT, Olive D. LIGHT, a new TNF superfamily member, is essential for memory $\mathrm{T}$ helper cell-mediated activation of dendritic cells. Eur J Immunol (2003) 33:3213-9. doi:10.1002/eji.200324410

53. Xu G, Liu D, Okwor I, Wang Y, Korner H, Kung SK, et al. LIGHT is critical for IL-12 production by dendritic cells, optimal CD4+ Th1 cell response, and resistance to Leishmania major. J Immunol (2007) 179:6901-9.

54. Nielsen JS, Nelson BH. Tumor-infiltrating B cells and T cells: working together to promote patient survival. Oncoimmunology (2012) 1:1623-5. doi:10.4161/ onci.21650

55. Moussion C, Girard JP. Dendritic cells control lymphocyte entry to lymph nodes through high endothelial venules. Nature (2011) 479:542-6. doi:10.1038/ nature 10540
56. Muniz LR, Pacer ME, Lira SA, Furtado GC. A critical role for dendritic cells in the formation of lymphatic vessels within tertiary lymphoid structures. J Immunol (2011) 187:828-34. doi:10.4049/jimmunol.1004233

57. Wendland M, Willenzon S, Kocks J, Davalos-Misslitz AC, Hammerschmidt SI, Schumann K, et al. Lymph node $\mathrm{T}$ cell homeostasis relies on steady state homing of dendritic cells. Immunity (2011) 35:945-57. doi:10.1016/j.immuni.2011.10. 017

58. Lo JC, Chin RK, Lee Y, Kang HS, Wang Y, Weinstock JV, et al. Differential regulation of CCL21 in lymphoid/nonlymphoid tissues for effectively attracting $\mathrm{T}$ cells to peripheral tissues. J Clin Invest (2003) 112:1495-505. doi:10.1172/JCI200319188

59. Paya CV, Kenmotsu N, Schoon RA, Leibson PJ. Tumor necrosis factor and lymphotoxin secretion by human natural killer cells leads to antiviral cytotoxicity. J Immunol (1988) 141:1989-95.

60. Pablos JL, Santiago B, Tsay D, Singer MS, Palao G, Galindo M, et al. A HEVrestricted sulfotransferase is expressed in rheumatoid arthritis synovium and is induced by lymphotoxin- $\alpha / \beta$ and TNF- $\alpha$ in cultured endothelial cells. BMC Immunol (2005) 6:6. doi:10.1186/1471-2172-6-6

61. Kar UK, Srivastava MK, Andersson A, Baratelli F, Huang M, Kickhoefer VA, et al. Novel CCL21-vault nanocapsule intratumoral delivery inhibits lung cancer growth. PLoS One (2011) 6:e18758. doi:10.1371/journal.pone.0018758

62. Kanagawa N, Niwa M, Hatanaka Y, Tani Y, Nakagawa S, Fujita T, et al. CCchemokine ligand 17 gene therapy induces tumor regression through augmentation of tumor-infiltrating immune cells in a murine model of preexisting CT26 colon carcinoma. Int J Cancer (2007) 121:2013-22. doi:10.1002/ijc.22908

63. Marinkovic T, Garin A, Yokota Y, Fu YX, Ruddle NH, Furtado GC, et al. Interaction of mature $\mathrm{CD} 3^{+} \mathrm{CD} 4^{+} \mathrm{T}$ cells with dendritic cells triggers the development of tertiary lymphoid structures in the thyroid. J Clin Invest (2006) 116:2622-32. doi:10.1172/JCI28993

64. Yang SC, Batra RK, Hillinger S, Reckamp KL, Strieter RM, Dubinett SM, et al. Intrapulmonary administration of CCL21 gene-modified dendritic cells reduces tumor burden in spontaneous murine bronchoalveolar cell carcinoma. Cancer Res (2006) 66:3205-13. doi:10.1158/0008-5472.CAN-05-3619

65. Yang SC, Hillinger S, Riedl K, Zhang L, Zhu L, Huang M, et al. Intratumoral administration of dendritic cells overexpressing CCL21 generates systemic antitumor responses and confers tumor immunity. Clin Cancer Res (2004) 10:2891-901. doi:10.1158/1078-0432.CCR-03-0380

66. Hillinger S, Yang SC, Zhu L, Huang M, Duckett R, Atianzar K, et al. EBVinduced molecule 1 ligand chemokine (ELC/CCL19) promotes IFN-gammadependent antitumor responses in a lung cancer model. J Immunol (2003) 171:6457-65.

67. Nomura T, Hasegawa H, Kohno M, Sasaki M, Fujita S. Enhancement of anti-tumor immunity by tumor cells transfected with the secondary lymphoid tissue chemokine EBI-1-ligand chemokine and stromal cell-derived factor-1 $\alpha$ chemokine genes. Int J Cancer (2001) 91:597-606. doi:10.1002/10970215(200002)9999:9999<::AID-IJC1107<3.0.CO;2-J

68. Kirk CJ, Hartigan-O'Connor D, Nickoloff BJ, Chamberlain JS, Giedlin M, Aukerman $\mathrm{L}$, et al. $\mathrm{T}$ cell-dependent antitumor immunity mediated by secondary lymphoid tissue chemokine: augmentation of dendritic cell-based immunotherapy. Cancer Res (2001) 61:2062-70.

69. Sharma S, Stolina M, Zhu L, Lin Y, Batra R, Huang M, et al. Secondary lymphoid organ chemokine reduces pulmonary tumor burden in spontaneous murine bronchoalveolar cell carcinoma. Cancer Res (2001) 61:6406-12.

70. Sharma S, Stolina M, Luo J, Strieter RM, Burdick M, Zhu LX, et al. Secondary lymphoid tissue chemokine mediates $\mathrm{T}$ cell-dependent antitumor responses in vivo. J Immunol (2000) 164:4558-63.

71. Mounzer RH, Svendsen OS, Baluk P, Bergman CM, Padera TP, Wiig H, et al. Lymphotoxin- $\alpha$ contributes to lymphangiogenesis. Blood (2010) 116:2173-82. doi:10.1182/blood-2009-12-256065

72. Mac Keon S, Gazzaniga S, Mallerman J, Bravo AI, Mordoh J, Wainstok R. Vaccination with dendritic cells charged with apoptotic/necrotic B16 melanoma induces the formation of subcutaneous lymphoid tissue. Vaccine (2010) 28:8162-8. doi:10.1016/j.vaccine.2010.09.095

73. Kobayashi Y, Kato K, Watanabe T. Synthesis of functional artificial lymphoid tissues. Discov Med (2011) 12:351-62.

74. Ware CF. Targeting lymphocyte activation through the lymphotoxin and LIGHT pathways. Immunol Rev (2008) 223:186-201. doi:10.1111/j.1600-065X.2008. 00629.x 
75. Lukashev M, LePage D, Wilson C, Bailly V, Garber E, Lukashin A, et al. Targeting the lymphotoxin- $\beta$ receptor with agonist antibodies as a potential cancer therapy. Cancer Res (2006) 66:9617-24. doi:10.1158/0008-5472.CAN-06-0217

76. Liang CM, Ye SL, Zhong CP, Zheng N, Bian W, Sun RX, et al. More than chemotaxis: a new anti-tumor DC vaccine modified by rAAV2-SLC. Mol Immunol (2007) 44:3797-804. doi:10.1016/j.molimm.2007.03.026

77. Terando A, Roessler B, Mulé JJ. Chemokine gene modification of human dendritic cell-based tumor vaccines using a recombinant adenoviral vector. Cancer Gene Ther (2004) 11:165-73. doi:10.1038/sj.cgt.7700671

78. Tripodi D, Conti F, Rosati M, Maccauro G, Saggini A, Cianchetti E, et al. IL-36 a new member of the IL-1 family cytokines. J Biol Regul Homeost Agents (2012) 26:7-14.

79. Vigne S, Palmer G, Martin P, Lamacchia C, Strebel D, Rodriguez E, et al. IL-36 signaling amplifies Th1 responses by enhancing proliferation and Th1 polarization of naive $\mathrm{CD}^{+} \mathrm{T}$ cells. Blood (2012) 120:3478-87. doi:10.1182/blood2012-06-439026

80. Frey S, Derer A, Messbacher ME, Baeten DL, Bugatti S, Montecucco C, et al. The novel cytokine interleukin-36 is expressed in psoriatic and rheumatoid arthritis synovium. Ann Rheum Dis (2013) 72:1569-74. doi:10.1136/annrheumdis2012-202264

81. Shaik Y, Sabatino G, Maccauro G, Varvara G, Murmura G, Saggini A, et al. IL-36 receptor antagonist with special emphasis on IL-38. Int J Immunopathol Pharmacol (2013) 26:27-36.

82. Vigne S, Palmer G, Lamacchia C, Martin P, Talabot-Ayer D, Rodriguez E, et al. IL-36R ligands are potent regulators of dendritic and T cells. Blood (2011) 118:5813-23. doi:10.1182/blood-2011-05-356873

83. Wang FH, Li YH, Li S, Jiang WQ, Guan ZZ. [Phase I clinical trial of intravenous recombinant human lymphotoxin-alpha derivative]. AiZheng (2006) 25: 501-4.

84. Baratelli F, Takedatsu H, Hazra S, Peebles K, Luo J, Kurimoto PS, et al. Preclinical characterization of GMP grade CCL21-gene modified dendritic cells for application in a phase I trial in non-small cell lung cancer. J Transl Med (2008) 6:38. doi:10.1186/1479-5876-6-38

85. Mulé JJ. Dendritic cell-based vaccines for pancreatic cancer and melanoma. Ann N Y Acad Sci (2009) 1174:33-40. doi:10.1111/j.1749-6632.2009.04936.x
86. Pasero C, Speiser DE, Derré L, Olive D. The HVEM network: new directions in targeting novel costimulatory/co-inhibitory molecules for cancer therapy. Curr Opin Pharmacol (2012) 12:478-85. doi:10.1016/j.coph.2012.03.001

87. Steinberg MW, Cheung TC, Ware CF. The signaling networks of the herpesvirus entry mediator (TNFRSF14) in immune regulation. Immunol Rev (2011) 244:169-87. doi:10.1111/j.1600-065X.2011.01064.x

88. Cai G, Freeman GJ. The CD160, BTLA, LIGHT/HVEM pathway: a bidirectional switch regulating T-cell activation. Immunol Rev (2009) 229:244-58. doi:10.1111/j.1600-065X.2009.00783.x

89. De Trez C, Schneider K, Potter K, Droin N, Fulton J, Norris PS, et al. The inhibitory HVEM-BTLA pathway counter regulates lymphotoxin receptor signaling to achieve homeostasis of dendritic cells. J Immunol (2008) 180:238-48.

90. Granger SW, Rickert S. LIGHT-HVEM signaling and the regulation of T cellmediated immunity. Cytokine Growth Factor Rev (2003) 14:289-96. doi:10.1016/ S1359-6101(03)00031-5

Conflict of Interest Statement: The authors, editor and chief editor declare that while the author Walter Storkus and the editor Lisa Butterfield are currently employed by the same institution, University of Pittsburgh, USA, there has been no conflict of interest during the review and handling of this manuscript, and the manuscript reviewers involved were from other institutions.

Received: 09 October 2013; paper pending published: 03 November 2013; accepted: 05 November 2013; published online: 29 November 2013.

Citation: Chen L, Fabian KL, Taylor JL and Storkus WJ (2013) Therapeutic use of dendritic cells to promote the extranodal priming of anti-tumor immunity. Front. Immunol. 4:388. doi: 10.3389/fimmu.2013.00388

This article was submitted to Molecular Innate Immunity, a section of the journal Frontiers in Immunology.

Copyright (c) 2013 Chen, Fabian, Taylor and Storkus. This is an open-access article distributed under the terms of the Creative Commons Attribution License (CC BY). The use, distribution or reproduction in other forums is permitted, provided the original author(s) or licensor are credited and that the original publication in this journal is cited, in accordance with accepted academic practice. No use, distribution or reproduction is permitted which does not comply with these terms. 